\title{
EDUCAÇÃO DO CAMPO E NEOLIBERALISMO: UMA BREVE TRAJETÓRIA DA EDUCAÇÃO NO MST
}

\author{
Andre Luiz de Souza \\ Vinicius Gaspechoski Aurélio ${ }^{2}$
}

\begin{abstract}
RESUMO: Este artigo objetivou compreender as nuanças da ideologia neoliberal sobre as políticas públicas educacionais voltadas para Educação do Campo no Estado brasileiro. Buscou-se refletir a partir de levantamento bibliográfico, de leituras e aproximações na tríade que compreende a Educação do Campo, as políticas públicas e a implantação do neoliberalismo no Brasil. Para isso, foi utilizada a teoria marxista como elemento estruturador do estudo. Recuou-se no tempo na tentativa de reconstruir os (des)caminhos trilhados pelas políticas públicas no Brasil ao longo de sua história. Este trabalho é resultado de uma pesquisa desenvolvida pela Pós-Graduação Lato Sensu em Educação do Campo, na Universidade Estadual do Oeste do Paraná, que teve por objetivo principal analisar os impactos das políticas públicas na educação do campo.
\end{abstract}

Palavras-chave: Neoliberalismo. Políticas Públicas. Educação do Campo.

\section{FIELD EDUCATION AND NEOLIBERALISM: A BRIEF TRACK OF EDUCATION IN THE MST}

\begin{abstract}
This article aims to understand the nuances of the neoliberal ideology on public educational policies focused on Field Education in the Brazilian State. It was sought to reflect from a bibliographical survey, from readings and approximations in the triad that includes Field Education, public policies and the implantation of neoliberalism in Brazil. For this, the Marxist theory was used as the structuring element of the study. He stepped back in time in an attempt to reconstruct the (un) paths taken by public policies in Brazil throughout its history. This work is the result of a research developed by Lato Sensu Postgraduate in Field Education, at the State University of the West of Paraná, whose main objective was to analyze the impacts of public policies on rural education.
\end{abstract}

Key-words: Neoliberalism. Public policy. Field Education.

\section{INTRODUÇÃO}

\footnotetext{
${ }^{1}$ Licenciatura plena em Ciências Sociais pela Universidade Estadual do Oeste do Paraná e bacharelado em Ciências Sociais pela mesma instituição (UNIOESTE).. Especialista em Educação do Campo e Agroecologia na Agricultura Familiar e Camponesa- Residência Agrária pela Universidade Estadual de CampinasSP.(UNICAMP) Mestrado em Ciências Sociais na Universidade Estadual do Oeste do Paraná (UNIOESTE). Atualmente é professor do Instituto Federal do Paraná (IFPR). Contato: andre-sociais @ hotmail.com

${ }^{2}$ Mestrando pelo Programa de Pós-Graduação Stricto Sensu em Sociedade, Cultura e Fronteiras da Universidade Estadual do Oeste do Paraná - UNIOESTE, Especialista em Educação do Campo pela UNIOESTE (2017),
} 
Este artigo objetivou explanar e discutir a educação brasileira, especificamente na trajetória dos diferentes períodos da história educacional do campo no Brasil, enfatizando a lógica capitalista em sua fase mais recente de difusão da ideologia neoliberal sobre as políticas públicas educacionais que afetam toda a sociedade. Foi buscado historicizar as propostas marcadas pelos organismos internacionais de mercado sobre o Brasil e seus impactos políticos, econômicos e culturais na estrutura social da nação. Além de demonstrar como a deserção do Estado, sob essa lógica, afeta não apenas a educação, mas toda a esfera social do país.

É salientado a historicidade da educação no Brasil, elencando como ela é passível de cooptação pelo sistema econômico vigente, tornando-se artigo de produção e de reprodução de uma classe no poder e em sua manutenção do status quo. E a partir desse desvendamento, é apontada também, a existente necessidade da classe proletária de se organizar em movimentos sociais em busca de seus direitos e de disputa por tal hegemonia.

É demonstrado, ainda, a existência concreta de uma política pública que não contempla os sujeitos do campo. O Programa Nacional de Educação do Campo PRONACAMPO é uma proposta do governo federal que na prática não encontra um chão permeado pela satisfação das necessidades do campo. A educação é apontada como serva a serviço da exploração pela classe dominante e de como assistimos nossos dirigentes políticos sistematicamente delegar a nossa subjetividade, nossa riqueza e nosso trabalho a uma ideologia a serviço do imperialismo norte americano e seus tentáculos que a tudo estão metidos.

\section{METODOLOGIA}

Esta pesquisa se caracteriza pela reflexão crítica a luz do materialismo histórico dialético, já que se pretende alcançar com esse método a visão da totalidade do objeto a ser pesquisado, que neste caso é: a política neoliberal acerca da Educação do Campo. Portanto, trata-se de uma pesquisa fundamentalmente qualitativa buscando demonstrar como ocorrem de forma objetiva quanto às políticas públicas educacionais destinadas a Educação do Campo.

Tendo em vista que a técnica de análise documental é altamente valiosa para o tratamento de dados qualitativos, esta pesquisa foi alicerçada nesta técnica. Para desvelar os aspectos novos e de reincidência do problema em questão, que é a influência neoliberal na 
educação brasileira, em especial na Educação do Campo, foram reunidos elementos que pudessem apontar para tais fatos. Para isso, foram utilizados documentos norteadores, como: leis, normas, acordos reguladores, dados estatísticos, matérias de jornais e revistas, além de textos científicos que discutissem o tema.

Para a compreensão dos eixos norteadores teórico-ideológicos do Movimento dos Trabalhadores Rurais Sem Terra - MST, e dos movimentos sociais do campo no Brasil, foi realizada uma análise documental por meio da coleta de dados secundários produzidos pelo MST relacionados à Educação. Para tanto, foram analisadas, cartilhas, cadernos de formação, revistas, boletins públicos do movimento, livros, documentos internos, arquivos da biblioteca do Instituto Técnico de Pesquisa e Reforma Agrária - ITEPA, localizado no município de São Miguel do Iguaçu-PR e textos publicados na Internet da própria página do movimento.

Além disso, foi utilizada a estrutura das bibliotecas da Universidade Estadual do Oeste do Paraná - UNIOESTE, e da Universidade Latino Americana - UNILA. Essa técnica constitui-se, segundo Lüdke e André (1986), ferramenta de suma importância para incrementar o conhecimento junto à coleta e ao tratamento de dados em pesquisas de caráter bibliográfico e qualitativo.

Em vista disso, a análise sob o neoliberalismo na Educação do Campo se baseia no levantamento bibliográfico e na discussão teórica acerca deste tema em questão, objetivando apreender as articulações e particularidades do momento histórico em que estes sujeitos estão inseridos, e portanto, sendo influenciados por tais políticas públicas que acabam por sugestionar nos modos de organização social dos mesmos.

\section{CONTEXTO HISTÓRICO DA EDUCAÇÃO DO CAMPO NO BRASIL}

Tentando remontar a história educacional brasileira, trouxemos à discussão a autora Vânia Cristina Pauluk de Jesus, que discorre sobre a educação do campo no Brasil, no qual vamos apontar a direção que tomou a educação orientada pela classe dominante no país.

De acordo com Jesus (2005), logo na primeira Constituição, em 1824, e até mesmo na Carta Magna de 1891, é possível entender que a educação estava sob o comando capitalista, pois fez dela sua serva, já que não havia preocupação com a educação do campo, por exemplo. O cenário desse campo era atrasado em relação aos países desenvolvidos, pois ainda viviam de técnicas arcaicas na agricultura e ainda se forjava no país a sua prematura industrialização. Nesse contexto, a educação no perímetro urbano ainda era dirigida apenas às classes médias, que mandavam seus filhos para estudar nas universidades da Europa. 
Conforme Frigotto (1991), citado Jesus (2005), é necessário superar as “visões que ora colocam a educação ao nível de infra-estrutura (produção imediata da mais valia), ora relegam apenas à função ideológica superestrutural, um aparelho ideológico do Estado" (FRIGOTTO, 1991 apud JESUS, 2005, p. 101).

No entanto, Jesus (2005) salienta que a necessidade de educação no campo só veio após um intenso processo migratório, conhecido como êxodo rural, que se deu a partir do início do século XX. Esse movimento foi chamado de ruralismo pedagógico, pois foi apenas uma tentativa de conter o processo migratório, que gerava uma explosão de problemas sociais nos grandes centros urbanos, e não passou de uma forma unicamente salvacionista do patronato agroexportador, que nada tinha a ver com o interesse dos sujeitos do campo.

Essa visão estritamente nacionalista só passou a ser confrontada mais firmemente pelos atores que não estavam satisfeitos com seus resultados, a partir de 1960, conforme pontuou Jesus (2005):

\begin{abstract}
A década de 1960 foi palco de uma intensa mobilização societária, onde os movimentos camponeses se intensificaram exigindo reforma agrária imediata. Seu lema era: "Reforma agrária na lei ou na marra!" Esses movimentos eram apoiados por organizações políticas e partidárias. Entre elas podemos citar: ULTABs (União de Lavradores e Trabalhadores Agrícolas do Brasil), impulsionada pelo PCB e Master (Movimento dos Agricultores Sem Terra), no RS, apoiado pelo PTB. Algumas organizações receberam o apoio da ala progressista da Igreja Católica. Os movimentos de esquerda ligados às Ligas Camponesas, colaboram para o aparecimento de movimentos populares, a saber: os Centros Populares de Cultura (CPC) e o Movimento de Educação de Base (MEB), os quais visavam ao resgate dos valores culturais, escolares e sociais dos trabalhadores do campo, realizando projetos de educação popular e alfabetização de adultos, tanto no espaço urbano como no rural. (JESUS, 2005, p. 23-24).
\end{abstract}

Em meio a esse contexto, surge um pensador da educação brasileira, tão caro a esse movimento pedagógico que dá voz para aqueles que historicamente foram excluídos; esse personagem é Paulo Freire. Jesus (2005) traz para o palco um educador que propõe, por meio da alfabetização, um projeto baseado na "libertação dos oprimidos", que vai para além do aprendizado em si, é uma proposta de conscientização e de formação dos sujeitos do campo, que agora se apropriam do conhecimento com a problematização de seu cotidiano.

E como essa pedagogia freiriana tem forte influência no cenário político, forças contrárias a esse processo de conscientização da população brasileira, que contempla também os sujeitos do campo, têm a tarefa de manutenção da "ordem" nacional, com participação estrangeira. Novos convênios são alicerçados entre Estados Unidos e Brasil, a chamada "Aliança para o Progresso", que tinha o principal objetivo estancar o processo reivindicatório 
de imediata reforma agrária, dá-se nesse período a instalação da Ditadura Militar no Brasil, no ano de 1964. E com o braço forte do exército nacional e a cartilha ideológica de mercado trazida pelos norte-americanos, há no país uma forte perseguição aos movimentos sociais do campo, onde tem agora seu direito de organização proibido, e seus "lideres exilados, presos e assassinados" (JESUS, 2005, p. 25)

Segundo Lopes e Macedo (2010), a partir de procedimentos de transferências instrumentais de teorizações voltadas a política pública educacional, o Brasil, por meio de acordos bilaterais como o programa norte americano de ajuda à América Latina, centrava-se na assimilação de modelos norte americanos, em sua grande maioria funcionalista, para ser implementado no país. Conforme destaca Araújo, houve a parceria do Ministério da Educação - MEC, com o organismo norte americano chamado de USAID ${ }^{3}$ :

[...] é convidada para dar suporte técnico e financeiro à educação, tendo outras funções tais como: dar assistência aos conselhos e secretarias estaduais de Educação, treinar a equipe de técnicos brasileiros em planejamento de ensino, etc. (ARAÚJO, 2009, p. 53).

Segundo Araújo (2009), os objetivos da USAID por meio da política da “Aliança para o Progresso" que se consolidou pela Lei 5.692/71, que norteou toda a política pública educacional no contexto do Regime Militar, era de dominação político e ideológica por meio da educação. A tarefa do Brasil nesse momento foi de acatar toda decisão direcionada à educação brasileira pela universidade norte americana, de San Diego State College Foundation, e por meio da imprensa escrita e de rádio propagar a população a importância desse projeto para a nação. Conforme Araújo (2009), o que não era dito nessas proliferações ideológicas, pode ser constatado e denunciado agora:

Embora a História tenha mostrado que o Regime Militar desenvolveu a indústria brasileira e modernizou a educação a partir dos seus interesses, em contrapartida, atrelaram o Brasil aos EUA, contraindo enormes dívidas para com aquela nação, a partir dos diversos acordos políticos e financeiros, dentre eles, os acordos MEC/USAID. (ARAÚJO, 2009, p. 54).

\footnotetext{
${ }^{3}$ Agência dos Estados Unidos para o Desenvolvimento Internacional (United States Agency for International Development).
} 
Esse desdobramento demonstra que o Golpe de Estado de 1964 não fora apenas um golpe na democracia e a perda da soberania nacional, mas também um golpe na educação brasileira.

A escola do campo sofre as minguas de carência de conteúdo, pois houve um intenso esvaziamento em detrimento à técnica, à burocracia e aos atores especialistas, lacaios dessa nova roupagem tão necessária ao capitalismo. Conforme Frigotto,

\begin{abstract}
A educação rural esteve direcionada à formação profissional, não priorizando um projeto social para o campo. Mas a LDBEN 5692/71 apresenta um avanço ao possibilitar a adequação das férias ao plantio e colheita do campo, o que infelizmente, ainda não acorre, nas escolas em que estivemos. Essa lei esteve articulada aos estudos econômicos de educação a partir do trabalho de Schultz, introduzindo o conceito de capital humano para explicar o investimento em educação, o de produtividade, taxa de retorno, custos de educação enquanto mercadoria (FRIGOTTO, 1999 apud JESUS, 2005, p.36).
\end{abstract}

A preocupação nesse momento está voltada, necessariamente, ao mercado, e o campo também demanda uma forte influência no capital, por isso, seu direcionamento é ideologicamente formado pela classe dominante, que solidifica um pensamento, individualista, conformista e de obediência, de preparação para o mercado. Um verdadeiro aparelho ideológico de transmissão político e religioso, uma ferramenta indispensável para o capital.

Com o passar dos anos, houve diversos movimentos nacionais que lutavam pela redemocratização política do Brasil, diversas correntes distintas caminhavam para um ponto de convergência em comum à saída do modelo ditatorial, que já se encontrava esgotado, pois conseguiu concluir seu objetivo, que era estancar um possível levante comunista, que assombrava toda América Latina no contexto da Guerra Fria, e consequentemente após 21 anos, tem o seu fim.

\title{
NEOLIBERALISMO NO BRASIL
}

O Neoliberalismo como política ideológica, segundo Gentili (1998), tem sua inauguração no início dos anos de 1970 com a origem da ditadura militar chilena e a deposição do governo de Salvador Allende, mas que se consolidou de fato somente após o trauma sofrido pelos países latino-americanos, e seus regimes ditatoriais, num processo lento de reabertura à democracia. Após a redemocratização, a América Latina tinha um perfil bem propício para a consolidação do poder hegemônico, de ideologia neoliberal. 
Adam Przeworski, citado por Gentili (1998), no texto "A falácia neoliberal”, define o período de difusão das receitas e dos princípios neoliberais de a era das ideologias. Nesse momento, de modo geral, se penetrou capilarmente a ideologia de mercado, no senso comum das elites, culturalmente e politicamente falando, ganhando força hegemônica no mundo todo, que tem os seus desdobramentos em todos os campos da vida social, com princípios que representam simbolicamente, e não somente, a construção de legitimação da desigualdade social e em suas formas mais dramáticas, culpabilizando os excluídos de sua condição e convencendo-o de uma mera fatalidade natural ou de má sorte.

Essa orquestração das elites, que operam nas políticas públicas educacionais, pode ser vislumbrada na chamada "despolitização" da escola, que, segundo Gentili (1996), trata-se de um "processo que se traduz na progressiva desintegração... da escola ...como esfera pública" (GENTILI, 1996, p. 28, grifos nossos), que faz com que a escola, perca sua função majoritária de direito social à própria educação no dever de habilitar os indivíduos a exercerem os fundamentais direitos humanos, como o direito ao trabalho, ao lazer, à participação política e até mesmo no pleno direito à felicidade. E essa despolitização nada mais é do que transferir a educação da esfera política para esfera mercadológica, reduzindo dessa forma a um produto a ser comercializado, comprado, adquirido como uma propriedade. E esse movimento também reduz e reconceitua o sentido de cidadania em seus aspectos mais amplos, passando a ser um cidadão privatizado: o consumidor.

Conforme destacou Frigotto,

Novas demandas dos organismos internacionais de financiamento (FMI, BID, BIRD) surgem baseadas nas categorias: sociedade do conhecimento, qualidade total, educação para competitividade, formação abstrata e polivalente, redefinindo as bases da teoria do capital humano. (FRIGOTTO, 2000 apud JESUS, 2005, p.27).

E ainda:

Nesse contexto, é aprovada a LDBEN 9394/96, a qual tratando especificamente da educação do campo deixa bem flexível a organização do currículo escolar, período escolar, para que possa contemplar a multiplicidade das realidades escolares. (JESUS, 2005, p. 27).

Esse movimento causa uma imensa desordem na educação nacional. Para Jesus (2005), a adesão a esses financiamentos internacionais é característica de submissão do país subdesenvolvido, de acordo com os interesses precisamente imperialistas. Medidas de ajustes 
econômicos são aprovadas no chamado "Consenso de Washington"4, de 1989, como “disciplina fiscal, priorização de gastos públicos, reforma tributária, liberalização financeira, regime cambial, liberalização comercial, investimento direto estrangeiro, privatização, desregulação e propriedade intelectual" (CARCANHOLO apud JESUS, 2005, p. 28).

O neoliberalismo, segundo Marrach (1996), teve sua força propagadora quando os EUA passaram a ter a hegemonia política e econômica do planeta de forma exclusiva. Tal vertente política ideológica acentua ao mercado a propriedade de ser auto regulável e de ter a capacidade de superação das crises econômicas, além de distribuir progressivamente vários benefícios em torno do planeta, em que as economias se encontram interligadas.

A proposta dessa vertente ideológica é de não intervenção do Estado (ou mínima intervenção) nas relações comerciais de bens e serviços. No entanto, percebemos que essa não intervenção do Estado no mercado só é praticada de fato quando a pretensão é fazer uso dela as políticas públicas sociais; todavia, quando o beneficiário é um burguês financeiro ou industrial, a intervenção é para uma política privada, e o Estado não mede esforços para socorrê-lo.

Torres (1996), citado Kölln (2013), nos aponta como eram os critérios utilizados pelo Banco Mundial, destinados a orientar as políticas educacionais aos países que firmavam acordos no recebimento de financiamentos:

\begin{abstract}
A elaboração de currículos sintonizados com as demandas do mercado; centralidade para a educação básica, com a redução de gastos com o ensino superior; ênfase na avaliação do ensino em termos dos produtos da aprendizagem e do valor custo/beneficio; centralidade da formação docente em serviço em detrimento da forma inicial; autonomia das escolas com o maior envolvimento das famílias; desenvolvimento de políticas compensatórias voltadas para os portadores de necessidades especiais e para as minorias culturais. (TORRES, 1996 apud KÖLLN, 2013, p. 62).
\end{abstract}

Essas orientações são verticalizadas, pois não há nenhum diálogo com os sujeitos (educadores), que receberam tais implementações, e podemos afirmar que caso os dirigentes do Estado brasileiro aceitaram tais condições é por haver um alinhamento em sua própria percepção de mundo com as sugeridas pelos grandes conselheiros e financiadores.

Esses "ajustes" são levados a ferro e fogo, pois diversos países credores têm a possibilidade de renegociação de suas dívidas externas, se de antemão implementarem tal cartilha em seu país. O Brasil faz essa barganha que coloca em cheque muitos investimentos

\footnotetext{
4 “A expressão Washington Consensus foi usada pela primeira vez por John Williamson, pesquisador do Institute
} 
na estrutura social, que agora passam a ser tratados como gastos. Inclusive fazem parte dessa falta de atenção, que agora por critérios de contrato não devem receber mais investimentos, mesmo se tratando dos setores mais delicados de toda e qualquer sociedade, como a saúde e a própria educação.

Como referendado anteriormente, Gentili (1996) lembra que:

O neoliberalismo ataca a escola pública a partir de uma série de estratégias privatizantes, mediante a aplicação de uma política de descentralização autoritária e, ao mesmo tempo, mediante uma política de reforma cultural que pretende apagar do horizonte ideológico de nossas sociedades a possibilidade mesma de uma educação democrática, pública e de qualidade para as massas. Uma política de reforma cultural que, em suma, pretende negar e dissolver a existência mesma do direito à educação (GENTILI, 1996, p. 244).

A educação pública é atacada, tanto na cidade quanto no campo. E sua falta de qualidade é, segundo a vertente neoliberal, decorrente por ser administrada pelo Estado. Ou seja, por ser pública, ela carece de "eficácia, eficiência e produtividade". Conforme Gentili (1998), a crise educacional é uma crise de "qualidade". Segundo o mesmo autor, o viés neoliberal coloca o fracasso da má distribuição de renda e da vida indigna do capitalismo, nas mãos do "Estado interventor", e não na sociabilidade cindida que reproduz as desigualdades sociais. O Estado interventor é o culpado da crise enfrentada pelas instituições educacionais. As estratégias para sair da crise educacional, segundo essa vertente, são em nível micro e macro institucional: primeiramente, a competitividade deve ser instaurada para resolver o problema da qualidade; segundo, a necessidade é de articular e subordinar a educação à lei de oferta e procura, ou seja, a partir da demanda do mercado, na transformação da educação em mercadoria. E ainda surge um personagem que deve ser consultado para que esse projeto seja consolidado, o que Gentili (1998) vai chamá-lo de o "expert”, ou seja, se nessa perspectiva o Estado interventor é o culpado da existência da crise, então um homem de negócio é o "salvador da pátria", pois o raciocínio neoliberal nesse ponto é sucinto. Se uma escola deve seguir as leis do mercado e dentro dela ser promovida a competição entre os alunos, ninguém melhor para aconselhar uma educação assim, do que os homens que triunfaram em um ambiente igual, no próprio mercado.

De acordo com Jesus (2005), os desdobramentos dessas políticas neoliberais, fazem parte também do contexto das escolas do campo, que sofrem com diversos problemas, como falta de estrutura, de funcionários, de escolas, de verba. Muitas vezes a professora é também 
merendeira, servente, diretora (como na polivalência do toyotismo), um verdadeiro descaso com a educação do campo. Além de ser considerada apenas como um apêndice da escola urbana, é também um modelo alheio aos sujeitos do campo, que ali residem.

As escolas do campo padecem mais com esse modelo neoliberal porque necessitam de maiores investimentos. Por exemplo, a geografia do campo faz da distância, entre uma escola e outra, das casas à escola, um obstáculo para a permanência dos alunos na escola, pois há um percurso maior entre o aluno e a escola, o que exige uma viagem de todos os dias e isso dificulta no processo de aprendizagem, além de ser um forte indício de abandono da escolarização.

Como nos afirma Jesus (2005),

Geralmente, nas escolas situadas no campo, ou naquelas que recebem seus sujeitos, o calendário escolar não respeita as épocas de plantio e colheita. Os alunos acabam se evadindo da escola, a fim de ajudarem os pais no trabalho agrícola. É preciso romper com o círculo a que os jovens são condenados, segundo GENTILI, McCOWAN "sair do campo para continuar a estudar, e estudar para sair do campo. Reafirmamos que é preciso estudar para viver no campo" (2003, p. 139). (JESUS, 2005, p. 32).

Jesus (2005) ainda salienta que

\begin{abstract}
Esses dados revelam que a população do campo não tem seu direito à educação assegurado pelo Estado brasileiro. A escola precisa estar no campo e ser do campo. Mesmo quando não há possibilidade de a escola continuar no campo, e seja necessário nuclearizar pequenas escolas, o critério para defini-la como do campo precisa ser seus sujeitos, suas necessidades, valores e modos de vida; ou seja, a origem de seus sujeitos e não apenas o espaço geográfico, no qual a escola está situada. Se os seus sujeitos vêm do campo, a escola precisa considerar isso na elaboração de sua proposta pedagógica e estar voltada ao atendimento de suas necessidades. (JESUS, 2005, p. 31-32).
\end{abstract}

Esse movimento de evasão educacional empurra os seus sujeitos ainda mais para margem da sociedade, pois, além de perderem seus espaços para o grande latifúndio e para as máquinas, perdem também o sentido de pertencimento, suas culturas e suas raízes. Isso porque foram deseducados pela sociabilidade capitalista, que os descartam em beneficio de seu desenvolvimento sistêmico.

O movimento neoliberal de transformar a educação, ora em uma mercadoria, ora em uma transmissora ideológica, tem por fundamento a transferência do aluno da educação pública para educação privada, pois esse aluno é considerado um fardo para o Estado, 
enquanto para o mercado ele é considerado um possível cliente. Então, o Estado mínimo forma uma educação a partir de um mero "economicismo educacional", o que significa dizer que não há espaço para se pensar uma educação omnilateral, totalizante, mas que deve ser sempre subjugada como uma mercadoria e, portanto, seu papel é circular no mercado sem o menor valor social. Cosmo e Fernandes (2008) salientam que isso está tão consolidado na hegemonia neoliberal, que a formação humana se encontra sob a égide do mercado e o economicismo se encontra acima da política educacional e dos direitos sociais.

Para abordarmos uma proposta de políticas públicas concreta com relação à educação do campo no Brasil, traremos neste texto tentando relacionar com nossa discussão o Programa Nacional de Educação do Campo - PRONACAMPO, um programa do governo federal que, com base no Decreto $n^{\circ} 7.352$ de 4 de Novembro de 2010 (final do governo Lula), é "fruto de mobilizações de entidades e organizações de trabalhadores, iniciadas, nestes termos, no final da década de 1990"(CALDART et al., 2012, p. 1) , que tem como ação uma política de educação do campo destinada a ampliação e qualificação e a oferta da educação básica e superior às populações do campo. O PRONACAMPO foi instituído pelo governo federal em 20 de março de 2012 (primeiro mandato da presidenta Dilma) e tem em suas propostas a base popular como indica o próprio documento orientador de implantação do governo:

O PRONACAMPO foi construído pelo Grupo de Trabalho coordenado pelo MEC/SECADI, formado pelo Conselho dos Secretários Estaduais de Educação CONSED, União dos Dirigentes Municipais de Educação - UNDIME, Confederação Nacional dos Trabalhadores da Agricultura - CONTAG, Movimento dos Trabalhadores e Trabalhadoras Sem Terra - MST, Federação dos Trabalhadores da Agricultura Familiar - FETRAF, Rede de Educação do Semi-Árido Brasileiro RESAB, Universidade de Brasília - UNB e Universidade Federal de Minas Gerais UFMG, atendendo a demandas dos sistemas de ensino e dos movimentos sociais. As propostas específicas para a implementação da política da educação quilombola foram discutidas com a Secretaria de Políticas para a Promoção da Igualdade Racial - SEPPIR, sendo submetido à consulta junto a Comissão Nacional Quilombola CONAQ.

No entanto, Caldart et al. (2012) percebem que as formatações do programa seguem a lógica muito mais aproximada da política de "educação rural", com todas as suas ênfases e ausências, "no que esse nome encarna historicamente na forma de pensar a política educacional para os trabalhadores do campo em nosso país" (CALDART et al., 2012, p.1), do que dos próprios sujeitos relacionados com a prática social da Educação do Campo.

\footnotetext{
${ }^{5}$ Sistematização realizada pelos membros do Fonec: Antonio Munarim, Eliene Novaes Rocha, Mônica Castagna Molina e Roseli Salete Caldart em Brasília de 15 a 17 de Agosto de 2012. Para citações, usamos a entrada: Caldart et al. (2012).
} 
Segundo as análises de Caldart et al. (2012), o PRONACAMPO abre um abismo entre as demandas sociais debatidas, exaustivamente, pelos sujeitos do campo, mesmo com as pressões da luta dos trabalhadores rurais, para se expressar muito mais em sua lógica a constituição da hegemonia do capital no campo, na formação de mão de obra barata para o agronegócio, abandonando a perspectiva de uma política efetiva "de um sistema público de educação escolar de qualidade para todos os trabalhadores do campo" (CALDART et al., 2012, p.17).

Portanto, trata-se de um programa que em si é insuficiente para atender aos interesses das populações provenientes do campo, que de forma bem direta seria ter os direitos de acesso à educação de qualidade para todos trabalhadores do campo, sendo muito mais uma expressão do neoliberalismo a serviço do capital financeiro concretamente na figura do agronegócio fazendo da técnica e da educação meros apêndices da acumulação do capital.

\section{CONSIDERAÇÕES FINAIS: O CONTRASTE EM JOGO}

As reminiscências no Brasil são a forja de uma educação voltada para o mercado e não para os sujeitos do campo e da cidade, que apenas tem em seu horizonte a pretensão de gerar lucros estratosféricos a uma classe social. Tal observação histórica remete que a educação se tornou uma propriedade privada com características que promovem a exclusão social da grande maioria em detrimento a uma pequena minoria. Frigotto (1999) destaca que as alternativas educacionais sofrem pela disputa hegemônica; por exemplo, de um lado, há uma educação pensada para qualificação humana, que responda diretamente aos interesses e às necessidades de uma nova metamorfose de reprodução do capital; de outro lado, uma educação voltada para as múltiplas necessidades humanas, ambas coexistindo numa mesma totalidade.

Uma perspectiva que não negue a importância da técnica, dos avanços científicos e dos processos educacionais, entretanto, percebendo que a definição de educação, nesse caso, se dá pela correlação de forças das diferentes classes sociais. De acordo com Frigotto (1999), o progresso técnico tem o poder de dilatar o grau de satisfação das necessidades humanas. No entanto, este progresso estando em uma "camisa de forças", que é do que se trata a lógica do lucro privado, acaba por ampliar a exclusão social, porém vale lembrar que isso não se trata de uma predestinação natural, mas algo produzido historicamente.

A célebre frase de Marx \& Engels, "A história de toda sociedade existente até hoje tem sido a história das lutas de classe." (MARX; ENGELS, 1995, p. 35) tece um 
apontamento a esse trabalho, como constatado, o Brasil do campo luta por sua educação que remonta a história entre aqueles que detêm os meios de produção e aqueles que têm apenas sua força de trabalho para vender; é composta também por aqueles que assolam os salários no mais baixo possível, pois compõem o exército industrial de reserva. E no campo também existe o valor negociado que sobrepõe o valor judiciado, a escravidão modernizada. Assim como a dualidade e a centralidade da dominação e dos dominados contida nessa frase, é necessário acabar também com a dualidade de distinção entre campo e cidade. Nesse mesmo texto, Marx e Engels advertem ser necessário o fim da propriedade privada e ainda diz que a Educação deve ser gratuita, pois os conhecimentos acumulados são produtos da humanidade e devem ser partilhados de igual comum a todos.

O marxismo tem trazido para a classe trabalhadora muitos ensinamentos, mostrando que a história da humanidade é a história da luta de classes, e que para romper com a hegemonia do capitalismo é necessário que a classe trabalhadora tenha um projeto paralelo, rompendo definitivamente com o modo de produção atual. O materialismo histórico dialético é um método de análise que possibilita aos trabalhadores em geral perceber o mundo, e acima de tudo transformá-lo. A Educação do Campo ultrapassa os limites das escolas, constitui ferramentas que impulsionam os sujeitos do campo a lutarem por espaços muitas vezes reprimidos pelo sistema agrário brasileiro. É nessa perspectiva que os movimentos sociais do campo representam elemento chave para elencar esse novo horizonte de lutas e de embates políticos em torno do conceito de Educação do Campo.

Trabalhar um conceito de educação além do que já está exposto pelo Estado, prescreve um novo paradigma de educação, que garante a sobrevivência dos povos do campo. A Educação do Campo garante resgaste dos valores humanos, a solidariedade de suas representações culturais. É neste sentido que a Educação do Campo rompe com o modelo atual de educação, dando-lhes possiblidade de pensar o seu próprio meio de existência através de sua realidade. O espaço rural representará não apenas um lugar de produção de alimentos para os centros urbanos, mas reestruturará a possiblidade e os modos de vidas, muitas vezes abandonados e desestruturados pelo modo de produção capitalista.

Por fim, que para que a educação seja de fato transformada é necessário que ela esteja ligada a um projeto mais amplo de transformação social. É necessário que ela venha ao encontro do projeto da classe trabalhadora, que ela seja gestada para a libertação humana.

Faz-se necessário, também, que a escola seja mais que escola, a universidade precisa ser mais que universidade. A escola precisa ser parte de uma totalidade formadora mais ampla porque as lutas pedagógicas não substituem as lutas sociais e políticas mais amplas. 


\section{REFERÊNCIAS}

ARAÚJO, J. A. A Usaid, O regime militar e a implantação das escolas polivalentes no Brasil. Revista Eletrônica da Fainor, Vitória da Conquista, v.2, n.1, p.87-101, jan./dez. 2009.

CALDART, R. S; MUNARIM, A; ROCHA, E. N; MOLINA, M. C; Fórum Nacional de Educação do Campo - FONEC Notas para análise do momento atual da Educação do Campo. Seminário Nacional - BSB, 15 a 17 de agosto 2012.

COSMO, C. C. \& FERNANDES, S. A. S. Neoliberalismo e educação - lógicas e contradições. 2003.2 Disponível em: <http://www.histedbr.fe.unicamp.br/acer_histedbr/seminario/seminario8/_files/gYCRdDvb.p df>. Acesso em: 14/05/2017.

FRIGOTTO, G. Educação e formação humana: ajuste neoconservador e alternativa democrática. Editora Vozes, Petrópolis, 1999.

GENTILI, P. A falsificação do consenso: simulacro e imposição na reforma educacional do neoliberalismo. Petrópolis, RJ: Vozes, 1998.

GENTILI, P. (Org.) Pedagogia da exclusão: crítica ao neoliberalismo em educação. 2. ed. Petrópolis: Vozes, 1996.

JESUS, V. C. P. A educação no campo na história educacional brasileira: alguns apontamentos. Ponta Grossa-PR, 2005.

LOPES, A.; MACEDO, E. Contribuições de Stephen Ball para o estudo de políticas de currículo. In: MAINARDES, J.; BALL, S. Políticas educacionais: questões e dilemas. 2010.

KÖLLN, A. J. As mudanças no mundo do trabalho, o labor educativo e a saúde: o caso dos professores do ensino fundamental da rede estadual de Foz do Iguaçu - PR. 2013. Dissertação (Mestrado Sociedade, Cultura e Fronteiras) - Universidade Estadual do Oeste do Paraná UNIOESTE, Foz do Iguaçu- PR.

LÜDKE, M.; ANDRÉ, M. E. D. A. Pesquisa em educação: abordagens qualitativas. São Paulo: Pedagógica e Universitária, 1986.

MARRACH, S. A. Neoliberalismo e Educação. In: GUIRALDELLI JUNIOR, P. (Org.). Infância, Educação e Neoliberalismo. São Paulo: Cortez, 1996. p. 42-56.

MARX, Karl \& ENGELS, Friedrich (1995). Manifesto do partido comunista. São Paulo, Escriba. 